\title{
EFEITO DA TRISTEZA EM CARACTERES VEGETATIVOS, PRODUTIVOS E INDUSTRIAIS DA LARANJEIRA 'VALENCIA’ ENXERTADA EM HÍBRIDOS SEGREGANDO PARA TOLERÂNCIA ${ }^{(1)}$
}

\author{
RITA BORDIGNON $^{(2)}$; HERCULANO PENNA MEDINA FILHO ${ }^{(2,5)}$; WALTER JOSÉ SIQUEIRA ${ }^{(3)}$; \\ ROSE MARY PIO ${ }^{(4)}$
}

\begin{abstract}
RESUMO
Investigaram-se os efeitos da tristeza dos citros causada pelo vírus CTV em caracteres vegetativos, produtivos e industriais da laranjeira 'Valência', enxertada em sete progênies híbridas de irmãos germanos segregando para tolerância a essa doença. Os híbridos são provenientes de cruzamentos controlados entre os porta-enxertos comerciais Poncirus trifoliata 'Davis A' (T), tangerina Sunki (S), laranja Azeda 'São Paulo'(A) e limão Cravo 'Limeira' (C). Estudaram-se dois lotes de híbridos: o primeiro contendo 298 indivíduos, sendo $20 \mathrm{~T}$ x S; $67 \mathrm{~S} \times \mathrm{T}$; $98 \mathrm{~S}$ × A; $48 \mathrm{C}$ x A e $65 \mathrm{~T} \times$ A. No segundo lote, investigaram-se 1.243 híbridos, sendo $845 \mathrm{~S} \times \mathrm{A} ; 240 \mathrm{~A} \times \mathrm{S} ; 139 \mathrm{C} \times \mathrm{A}$ e $19 \mathrm{~A} \times \mathrm{C}$. Devido à tristeza, a mortalidade no viveiro foi em torno de $21 \%$ e, entre sobreviventes transplantados para campo, outros $13 \%$ dos híbridos intolerantes morreram em um período de quatro anos. Nos híbridos sobreviventes, a tristeza reduziu em quatro anos, o diâmetro dos porta-enxertos intolerantes em $41 \%$, o diâmetro do enxerto em $45 \%$ e o índice de vigor vegetativo em $42 \%$. A massa dos frutos foi também reduzida, em média, em $22 \%$. A produção de frutos foi o caráter mais drasticamente afetado, sendo reduzido em $41 \%$ na primeira colheita, acentuando-se esse efeito nas demais, até atingir $90 \%$ na quinta colheita, com média de $85 \%$ em relação ao valor acumulado das cinco colheitas. A produtividade por área da projeção da copa sofreu também acentuada redução $(46 \%)$, indicando ser o decréscimo da produção proporcionalmente muito mais intenso que o do crescimento vegetativo. A relação entre os diâmetros do enxerto/porta-enxerto decresceu $7 \%$ nas plantas intolerantes. Embora pequena, indica que o crescimento vegetativo da copa tolerante exibiu um efeito mais intenso que o próprio porta-enxerto intolerante. A coloração externa dos frutos, o rendimento e o "ratio" do suco foram pouco afetados, enquanto a acidez aumentou, em média, $12 \%$ e o teor de sólidos solúveis aumentou significativamente, 14\% em média, nos híbridos intolerantes.
\end{abstract}

Palavras-chave: Citrus, CTV, porta-enxertos, produção, crescimento, ${ }^{\circ}$ Brix.

\section{ABSTRACT \\ EFFECT OF THE CITRUS TRISTEZA DISEASE ON VEGETATIVE, PRODUCTIVE AND INDUSTRIAL CHARACTERS OF 'VALENCIA' SWEET ORANGE GRAFTED ONTO HYBRID ROOTSTOCKS SEGREGATING FOR TOLERANCE}

The effect of the citrus tristeza disease caused by CTV on vegetative, productive, and industrial characters of the sweet orange 'Valencia' grafted onto seven hybrid progenies of full sibs segregating

( $\left.{ }^{1}\right)$ Recebido para publicação em 9 de dezembro de 2002 e aceito em 9 de maio de 2003.

$\left({ }^{2}\right)$ Centro de Análise e Pesquisa do Agronegócio do Café 'Alcides Carvalho', Instituto Agronômico (IAC), Caixa Postal 28, 13001-970 Campinas (SP). E-mail: rita@iac.sp.gov.br

$\left({ }^{3}\right)$ Centro de Pesquisa e Desenvolvimento de Recursos Genéticos Vegetais, Instituto Agronômico (IAC), Campinas (SP).

$\left({ }^{4}\right)$ Centro Avançado de Pesquisa Tecnológica do Agronegócio de Citros Sylvio Moreira, Instituto Agronômico (IAC), Caixa Postal 4, 13490-970 Cordeirópolis (SP).

(5) Com bolsa de produtividade em pesquisa do CNPq 
for tolerance was studied. The hybrids were originated from controlled crosses between the commercial rootstocks 'Davis A' Poncirus trifoliata (T), Sunki mandarin (S), 'São Paulo' sour orange (A) and 'Limeira' Rangpur lime (C). Two sets of hybrids were studied. The first was formed by 298 individuals, from which 20 were T x S, $67 \mathrm{~S} \times \mathrm{T}, 98 \mathrm{~S} \times \mathrm{A}, 48 \mathrm{C} \times \mathrm{A}$, and $65 \mathrm{~T} \times \mathrm{A}$. The second set had 1.243 hybrids, being $845 \mathrm{~S} \times \mathrm{A}$, $240 \mathrm{~A} \times \mathrm{S}, 139 \mathrm{C} \times \mathrm{A}$, and $19 \mathrm{~A} \times \mathrm{C}$. In the nursery, tristeza disease was responsible for $21 \%$ of death among the intolerant individuals, while among survivors transplanted to the field, an additional $13 \%$ died in a four-years period. Among the intolerant survivors in the field, tristeza reduced in four years rootstock diameter to $41 \%$, scion diameter in $45 \%$, and general vigor in $42 \%$. Fruit weight was reduced in $22 \%$ in average. Yield was the most drastically affected character, being reduced to $41 \%$ in the first harvest, and up to $90 \%$ in the fifth harvest. Accumulated yields of five years were reduced $85 \%$ in the intolerant segregants among the different groups of hybrids. Productivity (yield/area of canopy) was also intensely affected $(46 \%)$ indicating that the reduction in yield was proportionally more intense than the correspondent reduction in the vegetative growth. The relation between scion/rootstock diameters decreased $7 \%$ in the intolerant plants. Although small, it indicated that the vegetative growth of the tolerant canopies was more affected than the rootstocks, despite their intolerance. Little or no effect was detected on external peel color, juice outturn, and soluble solids/acids ratio. Acidity and soluble solids significantly increased at an average of 12 and $14 \%$, respectively, in the intolerant hybrids.

Key words: Citrus, CTV, yield, growth ${ }^{\circ}$ Brix.

\section{INTRODUÇÃO}

Desde a década de 30, quando da introdução da tristeza, são conhecidos no Brasil os efeitos gerais dessa doença, ao incidir em pomares cítricos estabelecidos com porta-enxertos intolerantes, como a laranja Azeda [Citrus aurantium (L.)]. Diminuição do crescimento, declínio na produção, depauperamento da planta, colapso do floema, podridão das radicelas e, em muitos casos, a subseqüente morte das plantas são sintomas típicos da tristeza dos citros (MoreIra, 1942; Bitancourt, 1944; Franco e Bacchi, 1944; Meneghini, 1946; Moreira et al., 1949). A partir dessa época, os extensivos testes de porta-enxertos e os novos conhecimentos sobre a doença mostraram que o cultivo comercial de laranjas doces e tangerinas, no Brasil só seria viável com a utilização de porta-enxertos tolerantes (MoreIRA et al., 1949; POMPEU JÚNIOR, 1990).

Embora os efeitos gerais da tristeza sejam, como mencionado, bem conhecidos ao infectar pomares adultos já estabelecidos, é difícil obter-se uma quantificação de seus efeitos, incidindo desde o início do desenvolvimento das mudas até a fase adulta de produção no campo. Em nossas condições, em que todas as copas de laranjeiras [C. sinensis (L.) Osb.] estão infectadas pelo vírus da tristeza dos citros (Citrus Tristeza Virus - CTV) e seu mais eficiente vetor, o pulgão preto (Toxoptera citricidus) encontra-se amplamente disseminado no campo, é extremamente difícil que um mesmo material genético seja avaliado no próprio local, em situação com e sem a doença. Assim, conhece-se o comportamento de porta-enxertos intolerantes em outras regiões onde a doença ainda não está disseminada. Alternativamente, em nossas condições, somente pode-se avaliar os efeitos gerais da tristeza pela comparação de uma mesma copa enxertada em grupos diferentes de porta-enxertos, tolerantes e intolerantes. Com isso, confundem-se os efeitos da doença com as influências do local de cultivo ou dos clones dos porta-enxertos, tornando, por essas razões, bastante difícil uma avaliação mais aproximada sobre o efeito específico da tristeza em diversas características agronômicas e tecnológicas.

Idealmente, o material mais indicado para o estudo desses efeitos seria linhas isogênicas de porta-enxertos, que diferissem apenas quanto aos alelos de tolerância, situação inexistente e, na prática, improvável de ser obtida. Tal quantificação pode, entretanto, ser razoavelmente estimada pelo estudo comparativo de grupos de indivíduos pertencentes a progênies híbridas de irmãos germanos de porta-enxertos, segregando para tolerância. Neste trabalho, investigaram-se os efeitos da tristeza em algumas características vegetativas, produtivas e industriais da laranjeira 'Valência' (C. sinensis), enxertada em sete progênies híbridas de irmãos germanos segregando para tolerância, as quais são oriundas de cruzamentos controlados entre quatro porta-enxertos comerciais.

\section{MATERIAL E MÉTODOS}

Os híbridos estudados foram obtidos por polinizações controladas após as devidas emasculações (BORDIGNON et al., 1990; BORDIGNON, 1995). Originados de embriões zigóticos, foram individualmente identificados por marcadores morfológicos (Toxopeus, 1962; BALLVÉ et al., 1997) e isoenzimáticos (BALLVÉ et al., 1991; 1995) e separados dos clones maternos nucelares (BORDIGNON, 2000). Enxertaram-se esses híbridos com copa de laranjeira 'Valência' do Banco de Matrizes, infectada com uma estirpe severa de CTV. Foram formados dois campos 
de observação e seleção (COS I e COS II), no Centro Avançado de Pesquisa Tecnológica do Agronegócio de Citros 'Sylvio Moreira' (CAPTA-Citros) do Instituto Agronômico (IAC), em Cordeirópolis (SP). Apesar de tais campos terem sido estabelecidos com os quatro clones nucelares dos parentais e diferentes grupos de híbridos, no presente trabalho são considerados apenas os grupos de híbridos a seguir relacionados, por conterem, em cada um, indivíduos tolerantes e intolerantes, apropriados, portanto, ao estudo proposto, como salientado ante-riormente.

Para o estabelecimento do COS I, as mudas foram formadas em viveiro e transplantadas para o campo no espaçamento de $8 \times 4 \mathrm{~m}$ e, no caso do COS II, transplantadas diretamente para o campo, em linhas duplas no espaçamento de $5 \times 1 \times 0,5 \mathrm{~m}$. No COS I estudaram-se 298 híbridos, sendo 20 de Poncirus trifoliata (L.) Raf. 'Davis A' (T) x tangerina Sunki (C. sunki Hort. ex Tan.) (S), 67 SxT, 98 tangerina Sunki $x$ laranja Azeda 'São Paulo' (C. aurantium L.)(A), 48 de limão Cravo 'Limeira' (C. limonia Osb.) (C) x laranja Azeda, 65 de Poncirus trifoliata x laranja Azeda.

No COS II investigaram-se 1.243 híbridos, sendo $845 \mathrm{~S} \times \mathrm{A}, 240 \mathrm{~A} \times \mathrm{S}, 139 \mathrm{C} \times \mathrm{A}$ e $19 \mathrm{~A} \times \mathrm{C}$.

Realizaram-se análises estatísticas paramétricas (Anova) com comparações de médias pelo teste " $\mathrm{t}$ ", e não paramétricas, com comparações de medianas pelo teste de Mood, correlações produto x momento (Pearson), bem como gráficos de dispersão com o auxílio do programa Minitab ${ }^{\circledR}$ Statistical Software, versão 13.

As identificações no Banco de Germoplasma dos parentais utilizados na obtenção dos híbridos, os critérios para classificação dos híbridos em tolerantes ou intolerantes, bem como os seus genótipos quanto aos locos $\mathrm{Az}$ e $t$ governando a tolerância à tristeza encontram-se em BORDIGNON et al. ${ }^{(5)}$.

Como a expressão mais drástica da tristeza é a morte da planta, determinou-se primeiramente a porcentagem de plantas mortas devido à doença nas fases de viveiro, de 1994 a 1996 e, posteriormente também no campo. O efeito da tristeza nos híbridos sobreviventes foi avaliado em diversos caracteres vegetativos, produtivos e industriais em vários anos. Assim, nos híbridos do COS I realizaram-se as seguintes determinações entre os anos de 1996 e 2000.

$\left(^{5}\right)$ BORDIGNEON, R.; MEDINA FILHO, H.P.; SIQUEIRA, W.J.; MULLER, G.W.; TEÓFILO SOBRINHO, J. Genetics of tolerance to the tristeza virus (CTV) in citrus rootstock. Genetics and molecular Biology, Ribeirão Preto., v.27, n.1, 2004 (no prelo). a) Diâmetro do porta-enxerto em 1996, 1998 e 2000: mediu-se, o perímetro do porta-enxerto com fita métrica, dividindo-se o valor obtido por p;

b) Diâmetro do enxerto em 1996 e 2000: obtido do mesmo modo que no item anterior, aproximadamente a $10 \mathrm{~cm}$ acima do ponto de enxertia;

c) Altura da planta em 1998 e 2000: medida com régua graduada de 5 em $5 \mathrm{~cm}$;

d) Diâmetro da copa em 1998 e 2000: calculado a partir da média das larguras das plantas em duas faces ortogonais;

e) Índice de vigor vegetativo em 1998 e 2000: calculado a partir da altura da planta, diâmetro da copa e do tronco do porta-enxerto, segundo a fórmu-

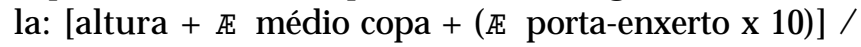
100;

f) Produção no período 1997-2001: produção individual por planta ( $\mathrm{kg}$ de frutos) em cada ano;

g) Massa do fruto em 1997, 1998, 1999: massa média de um máximo de dez frutos por planta em cada ano;

h) Coloração externa do fruto em 1999: avaliada visualmente no campo como um parâmetro que, em parte, reflete a maturação dos frutos conforme seu aspecto externo, de acordo com o seguinte critério: (1) muito precoce; (2) precoce; (3) entre média e precoce; (4) média; (5) entre média e tardia; (6) tardia; (7) muito tardia;

i) Qualidade industrial em 1999: avaliada pelo laboratório de qualidade do CAPTA-Citros, de acordo com métodos padronizados de avaliação industrial, determinando-se o teor de sólidos solúveis ( ${ }^{\mathrm{B} B r i x)}$ com refratômetro, acidez titulável (\%) por volume de suco, rendimento (\%) de suco pela massa do fruto, calculando-se também o ratio (razão ${ }^{\circ}$ Brix $/ \%$ acidez);

J) Compatibilidade entre o enxerto e o porta-enxerto em 2000: estimada através da relação entre o diâmetro do enxerto e o diâmetro do porta-enxerto, medidos a aproximadamente $3 \mathrm{~cm}$ acima e $3 \mathrm{~cm}$ abaixo da região de enxertia;

K) produtividade em 1999 e no período 19971999 por área da projeção da copa: calculada a partir da soma das produções ( $\mathrm{kg}$ de frutos) referentes a 1997, 1998 e 1999 e também apenas à produção de 1999, por ser esta a maior das três e, portanto, menos influenciada pela precocidade de início de produção dos diversos materiais. A área da projeção da copa foi calculada pela fórmula: Área $=p R^{2}$, sendo $R=1 / 2$ do diâmetro médio da copa em janeiro de 2000. No COS II, mediu-se diretamente, em 1998, o diâmetro do enxerto com auxílio de uma régua com cursor. 


\section{RESULTADOS E DISCUSSÃO}

Com relação às plantas do Campo de Observação e Seleção I, verificou-se que a incidência da tristeza, após a fase de formação das mudas, foi bastante prejudicial, causando já no viveiro $21 \%$ de mortalidade, em média. Entre os sobreviventes transplantados para o campo, outros $13 \%$ dos híbridos intolerantes vieram a morrer em um período de quatro anos, evidenciando a conhecida severidade dessa doença.

Os valores médios obtidos nas diversas avaliações dos caracteres estudados encontram-se nos quadros 1, 2 e 3 . Em cada grupo de híbridos, o efeito da tristeza nos segregantes intolerantes se fez notar, na grande maioria dos casos, de forma e intensidades semelhantes. A figura 1 mostra as distribuições desses valores nos grupos de indivíduos tolerantes e intolerantes de cada progênie híbrida.

De maneira geral, os caracteres produtivos (massa do fruto, produção e produtividade) foram os mais afetados, seguidos dos vegetativos (vigor, altura e diâmetros), enquanto os industriais mostraram-se pouco afetados. O quadro 2 evidencia os efeitos da tristeza em valores percentuais dos híbridos intolerantes em relação aos seus irmãos germanos tolerantes.

Assim, o diâmetro do porta-enxerto foi, nos diversos anos, em média, 36\% menor nos indivíduos intolerantes, variando de $29 \%$ a $42 \%$ nos diversos grupos de híbridos. Observou-se sensível redução $(24,2 \%)$, identificada desde 1996, logo após o plantio das mudas no campo. Essa redução, após dois anos, acentuou-se sobremaneira, atingindo mais de $43 \%$ em 1998.

De forma semelhante, o mesmo comportamento foi notado para o diâmetro do enxerto, que atingiu, em $2000,45 \%$ de redução. Nesse mesmo ano, verificou-se uma redução de $37 \%$ e $49 \%$, respectivamente, na altura e diâmetro da copa, refletindo em redução média de $42 \%$ no índice de vigor vegetativo. No COS II a redução no diâmetro do enxerto (Quadro 3) foi ainda mais acentuada $(73,3 \%)$, provavelmente devido à intensa competição entre os híbridos, plantados em denso espaçamento e também à condição mais estressante das plantas no campo que no viveiro. Esses valores refletem o efeito da tristeza no depauperamento geral da planta. A massa dos frutos também foi reduzida em todos os grupos de híbridos, nas três primeiras colheitas, anos em que se avaliou esse caráter. Os percentuais de redução desse caráter variaram de $14 \%$ a $42 \%$ sendo, em média, a redução de $22,5 \%$.
Por certo, dentre todos os caracteres estudados, o mais drasticamente afetado foi a produção. Já na primeira colheita, em 1997, apresentou um percentual de decréscimo de $41 \%$ atingindo quase $90 \%$ na quinta colheita, em 2001. O decréscimo na produção variou nos diversos híbridos entre $76 \%$ e $99 \%$ (média de $85,4 \%$ ) em relação ao valor acumulado (1997-2001) das cinco colheitas. Esse fato vem atestar a importância econômica da tristeza e ilustrar seu conhecido histórico de devastação nos países onde foi introduzida (BENNETT e Costa, 1949; RoISTACHeR et al., 1991; LeE et al., 1994).

Cabe ressaltar que não somente a produção e o vigor vegetativo foram bastante afetados pela tristeza, como também a produtividade das plantas por área, estimada pela relação da produção de frutos por área da projeção da copa. A redução nesse caráter foi também muito acentuada (46\% entre 1997 e 1999); esse decréscimo na produção das plantas foi mais que proporcional ao decréscimo no crescimento vegetativo. De forma indireta, indica a impossibilidade, no campo, de se compensar os efeitos da tristeza em copas tolerantes sobre porta-enxertos intolerantes, mediante um adensamento proporcional à redução do crescimento das plantas.

Com relação à compatibilidade enxerto/porta-enxerto, avaliada pela relação entre os diâmetros dos seus caules, verificou-se que essa relação diminuiu, em média, 7,4\%. Nos cinco grupos de híbridos observou-se uma redução variando entre $2 \%$ e $12 \%$. Para tal relação reduzir, é necessário que os porta-enxertos aumentem ou os enxertos diminuam em maior proporção àqueles. A diminuição relativa nesse caráter foi pequena, porém, não significativa somente no grupo de híbridos Trifoliata x Sunki. Os valores desse índice, em todos os grupos de híbridos, foram maiores nas plantas tolerantes do que nas intolerantes, mostrando, dessa forma, que essa relação também foi afetada pela tristeza. De fato, ao se analisar os valores percentuais (Quadro 2) referentes aos diâmetros dos porta-enxertos e dos enxertos, verifica-se que as reduções médias tanto em 1996 quanto em 2000 foram mais intensas nos enxertos que nos porta-enxertos. Esse fato indica que, na interação copa tolerante/porta-enxerto intolerante, o crescimento vegetativo do porta-enxerto, apesar de sua intolerância, foi proporcionalmente menos afetado que o da copa, que é tolerante. Em que pese as complexas inter-relações fisiológicas entre a copa e o porta-enxerto, seria de interesse maiores estudos sobre a ação da tristeza nesse sistema.

Outro aspecto interessante é a redução no vigor das plantas, observada em 2000, já se faria notar quatro anos antes, nos diâmetros dos porta-enxertos e dos enxertos dos híbridos intolerantes, $24 \%$ e $38 \%$ menores respectivamente (Quadro 2). 

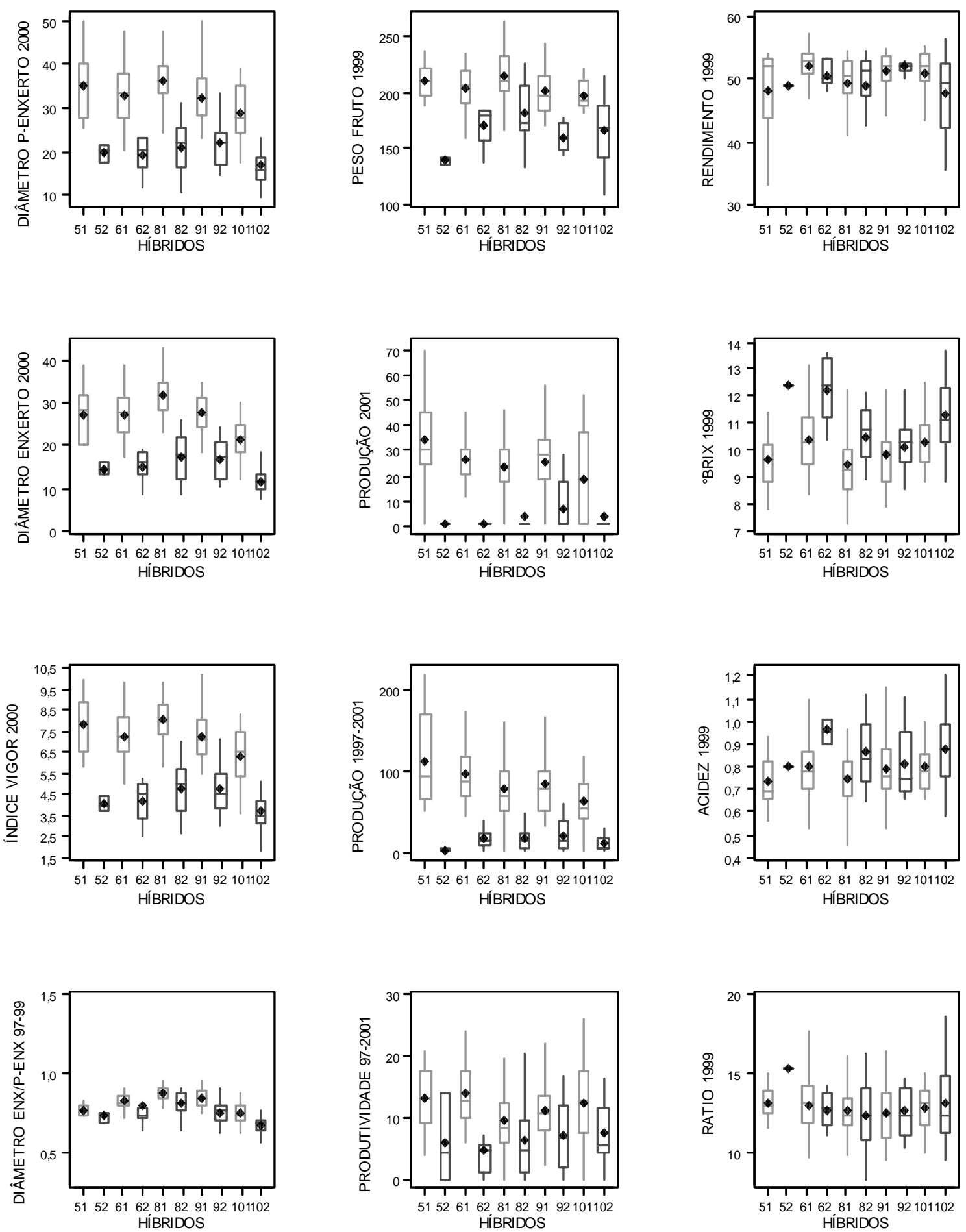

Figura 1. Diagramas de distribuição dos valores, nos anos indicados, de alguns caracteres de laranjeira 'Valência' [Citrus sinensis (L.) Osb.] enxertadas em híbridos segregando para tolerância à tristeza. Caixa central dividida pela mediana, com a média assinalada, compreende o 2 . $^{\circ}$ e 3..$^{\circ}$ quartis com $50 \%$ dos valores centrais. Identificação 51 e 52 correspondem respectivamente aos híbridos tolerantes e intolerantes de Poncirus trifoliata (L.) Raf. (T) x C. sunki Hort. ex Tan. (S), 61 e 62 à S x T, 81 e 82 a S x C. aurantium (L.) (A), 91 e 92 a C. limonia Osb. (C) x A e 101 e 102 a T $x$ A. 
Quadro 1. Valores médios, nos anos indicados, de caracteres vegetativos, produtivos e industriais da laranjeira 'Valência' [Citrus sinensis (L.) Osb.] enxertada em 168 híbridos tolerantes (Tol.) e 90 intolerantes (Intol.) à tristeza, referentes aos cruzamentos entre Poncirus trifoliata (L.) Raf. (Trifoliata), C. sunki Hort. ex Tan. (Sunki), C. aurantium (L.) (Azeda) e C. limonia Osb. (Cravo)

\begin{tabular}{|c|c|c|c|c|c|c|c|c|c|c|c|c|c|c|c|c|c|c|c|c|c|}
\hline \multirow{2}{*}{ Caráter } & \multirow{2}{*}{ Anos } & \multicolumn{4}{|c|}{ Trifoliata x Sunki } & \multicolumn{4}{|c|}{ Sunki x Trifoliata } & \multicolumn{4}{|c|}{ Sunki x Azeda } & \multicolumn{4}{|c|}{ Cravo x Azeda } & \multicolumn{4}{|c|}{ Trifoliata x Azeda } \\
\hline & & Tol. & Intol. & $t$ & $M$ & Tol. I & Intol. & $t$ & $M$ & Tol. & Intol. & $t$ & $M$ & Tol. & Intol. & $t$ & $M$ & Tol. & Intol. & $t$ & M \\
\hline Diâmetro & 1996 & 2,4 & 1,8 & ns & ns & 2,4 & 1,6 & * & * & 2,2 & 1,6 & * & * & 2,1 & 1,7 & ns & * & 2,3 & 1,9 & ns & ns \\
\hline \multirow[t]{2}{*}{ do porta-enxerto $(\mathrm{cm})$} & 1998 & 9,0 & 4,0 & * & * & 8,4 & 4,9 & * & * & 8,6 & 5,1 & * & $*$ & 8,0 & 5,1 & * & * & 7,3 & 4,3 & * & * \\
\hline & 2000 & 34,9 & 19,3 & $*$ & * & 32,7 & 19,0 & * & * & 36,2 & 20,8 & * & $*$ & 32,3 & 21,6 & $*$ & * & 28,7 & 16,5 & * & * \\
\hline \multirow[t]{2}{*}{ Diâmetro do enxerto $(\mathrm{cm})$} & 1996 & 1,5 & 0,8 & ns & * & 1,6 & 1,0 & * & * & 1,6 & 1,0 & * & $*$ & 1,7 & 1,1 & * & * & 1,5 & 1,0 & * & * \\
\hline & 2000 & 27,1 & 14,3 & $*$ & * & 27,0 & 15,0 & * & * & 32,1 & 17,3 & * & $*$ & 27,6 & 16,5 & * & * & 21,5 & 11,2 & * & * \\
\hline \multirow[t]{2}{*}{ Altura da planta $(\mathrm{cm})$} & 1998 & 195,0 & 100,0 & * & * & 186,9 & 112,0 & * & $*$ & 200,0 & 126,8 & * & * & 182,8 & 123,4 & $*$ & * & 167,1 & 102,9 & * & * \\
\hline & 2000 & 213,8 & 116,7 & * & * & 197,6 & 127,0 & $*$ & $*$ & 229,6 & 144,0 & * & * & 200,7 & 140,6 & $*$ & * & 177,8 & 112,0 & $*$ & * \\
\hline \multirow[t]{2}{*}{ Diâmetro da copa $(\mathrm{cm})$} & 1998 & 141,6 & 76,7 & $*$ & * & 136,7 & 78,2 & * & * & 141,5 & 81,5 & * & * & 134,6 & 80,9 & * & * & 123,9 & 69,1 & * & * \\
\hline & 2000 & 218,0 & 90,7 & * & $*$ & 204,4 & 100,9 & * & * & 217,1 & 120,1 & * & $*$ & 199,0 & 120,3 & * & * & 170,7 & 87,5 & * & * \\
\hline $\begin{array}{l}\text { Compatibilidade } \\
\text { enxerto/porta-enxerto }\end{array}$ & 2000 & 0,77 & 0,74 & ns & ns & 0,83 & 0,81 & ns & * & 0,89 & 0,82 & * & * & 0,86 & 0,76 & * & * & 0,75 & 0,67 & * & * \\
\hline \multirow{2}{*}{ Índice de vigor vegetativo } & 1998 & 4,3 & 2,3 & * & * & 4,1 & 2,4 & * & * & 4,3 & 2,6 & * & $*$ & 4,0 & 2,6 & * & $*$ & 3,6 & 2,2 & * & * \\
\hline & 2000 & 7,8 & 4,0 & * & * & 7,3 & 4,2 & * & * & 8,1 & 4,7 & * & $*$ & 7,2 & 4,8 & * & * & 6,4 & 3,6 & * & * \\
\hline \multirow[t]{3}{*}{ Massa do fruto $(g)$} & 1997 & 214,8 & 127,5 & $*$ & * & 210,9 & 160,7 & $*$ & * & 207,4 & 174,8 & * & ns & 197,2 & 143,8 & * & $*$ & 185,6 & 144,8 & $*$ & ns \\
\hline & 1998 & 219,6 & 157,0 & * & * & 223,9 & 183,1 & * & * & 228,1 & 194,2 & * & * & 207,6 & 178,7 & * & * & 217,4 & 171,1 & * & * \\
\hline & 1999 & 193,7 & 127,0 & $*$ & * & 177,3 & 146,5 & * & * & 190,5 & 157,8 & * & $*$ & 177,4 & 150,1 & * & * & 190,6 & 152,6 & $*$ & * \\
\hline Produção $(\mathrm{kg}$ de frutos & 1997 & 2,2 & 0,4 & ns & $*$ & 1,7 & 1,1 & ns & ns & 0,5 & 0,5 & ns & ns & 1,5 & 1,1 & ns & ns & 2,3 & 0,9 & * & * \\
\hline \multirow[t]{5}{*}{ por planta) } & 1998 & 13,3 & 5,6 & ns & ns & 11,0 & 2,1 & * & * & 4,5 & 1,6 & ns & * & 5,5 & 1,4 & ns & $*$ & 6,8 & 2,2 & * & ns \\
\hline & 1999 & 34,6 & 0,1 & * & * & 33,2 & 1,8 & * & * & 30,5 & 6,9 & $*$ & * & 27,5 & 7,8 & $*$ & * & 19,1 & 2,4 & * & * \\
\hline & 2000 & 27,5 & 0,0 & * & * & 23,8 & 8,9 & * & * & 18,5 & 3,4 & * & $*$ & 22,0 & 3,1 & * & * & 15,1 & 0,3 & * & * \\
\hline & 2001 & 34,3 & 0,0 & * & $*$ & 26,2 & 0,0 & * & * & 23,0 & 2,9 & * & * & 25,5 & 6,2 & * & * & 18,4 & 2,7 & * & * \\
\hline & $97-01$ & 111,8 & 1,1 & $*$ & * & 95,9 & 13,9 & * & $*$ & 76,9 & 15,7 & * & $*$ & 81,9 & 19,6 & * & * & 61,5 & 8,7 & * & * \\
\hline \multirow[t]{2}{*}{ Produtividade $\left(\mathrm{kg} / \mathrm{m}^{2}\right)$} & 1999 & 9,3 & 0,1 & $*$ & $*$ & 9,9 & 1,3 & * & * & 8,2 & 4,3 & * & $*$ & 9,0 & 4,4 & * & * & 8,4 & 2,3 & * & * \\
\hline & $97-99$ & 13,4 & 6,2 & ns & ns & 14,1 & 4,7 & $*$ & * & 9,6 & 6,4 & * & ns & 11,5 & 7,2 & $*$ & ns & 12,4 & 7,5 & * & * \\
\hline Coloração externa & 1999 & 4,0 & 4,0 & ns & ns & 3,4 & 3,4 & ns & ns & 4,0 & 4,7 & * & ns & 3,9 & 4,2 & ns & ns & 3,7 & 3,8 & ns & ns \\
\hline Rendimento do suco (\%) & 1999 & 48,0 & 48,9 & ns & ns & 52,2 & 50,5 & ns & ns & 49,1 & 49,0 & ns & ns & 51,3 & 52,0 & ns & ns & 50,6 & 47,6 & ns & ns \\
\hline${ }^{\circ}$ Brix & 1999 & 9,7 & 12,4 & * & $*$ & 10,4 & 12,2 & $*$ & $*$ & 9,4 & 10,5 & * & * & 9,8 & 10,1 & ns & ns & 10,3 & 11,3 & * & * \\
\hline Acidez titulável (\%) & 1999 & 0,7 & 0,8 & ns & ns & 0,8 & 1,0 & $*$ & $*$ & 0,7 & 0,9 & * & $*$ & 1,0 & 0,8 & ns & ns & 0,8 & 0,9 & ns & * \\
\hline “Ratio” & 1999 & 13,3 & 15,4 & ns & ns & 13,2 & 12,8 & ns & ns & 12,8 & 12,4 & ns & ns & 12,6 & 12,7 & ns & ns & 13,0 & 13,3 & ns & ns \\
\hline
\end{tabular}

ns, *: Significância ao nível de $5 \%$, da média pelo teste $t(t)$ e da mediana pelo teste de Mood $(M)$. Dados referentes ao Campo de Observação e Seleção I. 
Quadro 2. Efeitos da tristeza em caracteres vegetativos, produtivos e industriais da laranjeira 'Valência' [Citrus sinensis (L.) Osb.] enxertada em híbridos entre Poncirus trifoliata (L.) Raf. (T), C. sunki Hort. ex Tan. (S), C. aurantium (L.) (A) e C. limonia Osb. (C). São indicadas as reduções (-) ou acréscimos (+) percentuais nos valores médios dos híbridos tolerantes em relação aos intolerantes de cada cruzamento, nos anos indicados

\begin{tabular}{|c|c|c|c|c|c|c|c|}
\hline Caráter & & $\mathrm{T} \times \mathrm{S}$ & $\mathrm{S} \times \mathrm{T}$ & $\mathrm{S} \times \mathrm{A}$ & $\mathrm{C} \times \mathrm{A}$ & $\mathrm{T} \times \mathrm{A}$ & Média \\
\hline \multicolumn{8}{|l|}{ Diâmetro do porta-enxerto } \\
\hline & 1996 & -25 & -33 & -27 & -19 & -17 & $-24,2$ \\
\hline & 1998 & -56 & -42 & -41 & -36 & -41 & $-43,2$ \\
\hline & 2000 & -45 & -42 & -43 & -33 & -43 & $-41,2$ \\
\hline & Média & $-42,0$ & $-39,0$ & $-37,0$ & $-29,3$ & $-33,7$ & $-36,2$ \\
\hline \multirow[t]{3}{*}{ Diâmetro do enxerto } & 1996 & -47 & -38 & -38 & -35 & -33 & $-38,2$ \\
\hline & 2000 & -47 & -44 & -46 & -40 & -48 & $-45,0$ \\
\hline & Média & $-47,0$ & $-41,0$ & $-42,0$ & $-37,5$ & $-40,5$ & $-41,6$ \\
\hline \multirow[t]{3}{*}{ Altura da copa } & 1998 & -49 & -40 & -37 & -32 & -38 & $-39,2$ \\
\hline & 2000 & -45 & -36 & -37 & -30 & -37 & $-37,0$ \\
\hline & Média & $-47,0$ & $-38,0$ & $-37,0$ & $-31,0$ & $-37,5$ & $-38,1$ \\
\hline \multirow[t]{3}{*}{ Diâmetro da copa } & 1998 & -46 & -43 & -42 & -40 & -44 & $-43,0$ \\
\hline & 2000 & -58 & -51 & -45 & -40 & -49 & $-48,6$ \\
\hline & Média & $-52,0$ & $-47,0$ & $-43,5$ & $-40,0$ & $-46,5$ & $-45,8$ \\
\hline \multicolumn{8}{|c|}{ Compatibilidade enxerto/porta-enxerto } \\
\hline & 2000 & -4 & -2 & -8 & -12 & -11 & $-7,4$ \\
\hline \multirow[t]{3}{*}{ Índice de vigor vegetativo } & 1998 & -47 & -41 & -40 & -30 & -39 & $-39,4$ \\
\hline & 2000 & -49 & -42 & -42 & -33 & -44 & $-42,0$ \\
\hline & Média & $-48,0$ & $-41,5$ & $-41,0$ & $-31,5$ & $-41,5$ & $-40,7$ \\
\hline \multirow[t]{4}{*}{ Massa do fruto } & 1997 & -41 & -24 & -16 & -27 & -22 & $-26,0$ \\
\hline & 1998 & -29 & -18 & -15 & -14 & -21 & $-19,4$ \\
\hline & 1999 & -42 & -17 & -17 & -15 & -20 & $-22,2$ \\
\hline & Média & $-37,3$ & $-19,7$ & $-16,0$ & $-18,7$ & $-21,0$ & $-22,5$ \\
\hline \multirow[t]{7}{*}{ Produção } & 1997 & -82 & -35 & 0 & -27 & -61 & $-41,0$ \\
\hline & 1998 & -58 & -81 & -64 & -75 & -68 & $-69,2$ \\
\hline & 1999 & -99 & -95 & -77 & -72 & -87 & $-86,0$ \\
\hline & 2000 & -100 & -63 & -82 & -86 & -98 & $-85,8$ \\
\hline & 2001 & -100 & -100 & -87 & -76 & -85 & $-89,6$ \\
\hline & $97-01$ & -99 & -86 & -80 & -76 & -86 & $-85,4$ \\
\hline & Média & $-89,7$ & $-76,7$ & $-65,0$ & $-68,7$ & $-80,8$ & $-76,2$ \\
\hline \multirow[t]{3}{*}{ Produtividade } & 1999 & -99 & -87 & -48 & -51 & -73 & $-71,6$ \\
\hline & $97-99$ & -54 & -67 & -33 & -37 & -40 & $-46,2$ \\
\hline & Média & $-76,5$ & $-77,0$ & $-40,5$ & $-44,0$ & $-56,5$ & $-58,9$ \\
\hline Coloração externa & 1999 & 0 & 0 & +17 & +8 & +3 & $+5,6$ \\
\hline Rendimento suco & 1999 & +2 & -3 & 0 & +1 & -6 & $-1,2$ \\
\hline${ }^{\circ}$ Brix & 1999 & +28 & +17 & +12 & +3 & +10 & $+14,0$ \\
\hline Acidez titulável & 1999 & +14 & +25 & +29 & -20 & +13 & $+12,2$ \\
\hline “Ratio” & 1999 & +16 & -3 & -3 & +1 & +2 & $+2,6$ \\
\hline
\end{tabular}

Dados referentes ao Campo de Observação e Seleção I. 
Quadro 3. Reduções percentuais nos valores médios obtidos em 1998 no Campo de Observação e Seleção II do diâmetro $(\mathrm{cm})$ do caule da laranjeira 'Valência' [Citrus sinensis (L.) Osb.] enxertada em híbridos tolerantes e intolerantes à tristeza, correspondentes aos cruzamentos entre os parentais C. sunki Hort. ex Tan. (Sunki), C. aurantium (L.) (Azeda) e C. limonia Osb. (Cravo). Total de 1243 híbridos, sendo 729 tolerantes e 514 intolerantes

\begin{tabular}{|c|c|c|c|c|c|}
\hline Híbridos & Tolerantes & Intolerantes & Redução & $t$ & M \\
\hline & & & $\%$ & & \\
\hline Sunki x Azeda & 3,4 & 1,0 & 71 & * & * \\
\hline Azeda $\times$ Cravo & 3,2 & 0,7 & 78 & * & * \\
\hline Cravo x Azeda & 2,4 & 0,7 & 71 & * & * \\
\hline Azeda $\times$ Cravo & 2,6 & 0,8 & 69 & $*$ & * \\
\hline Média & - & - & 73,3 & - & - \\
\hline
\end{tabular}

* Médias e medianas significativas ao nível de 5\%, respectivamente, pelo teste $t(t)$ e Mood $(M)$.

Confirmando essas observações, cabe ressaltar os valores significativos $(\mathrm{P}<0,05)$ das correlações de Pearson obtidas entre essas duas avaliações (19962000). Para os híbridos T x S, S x T, S x A, C x A e T x A, respectivamente, esses valores foram $0,62,0,40$, $0,53,0,40$ e 0,39 para os porta-enxertos e $0,76,0,51$, $0,59,0,51$ e 0,47 para os enxertos.

Quanto aos caracteres industriais, verificouse que a maturação, avaliada com ressalvas pela coloração da casca, não foi afetada significativamente, embora as três únicas diferenças tenham mostrado tendência em intensificar a maturação $(+5,6 \%)$. O rendimento do suco não foi alterado, sendo as pequenas diferenças obtidas parte positivas, parte negativas, não significativas.

Os teores de sólidos solúveis representados pelos valores de ${ }^{\circ}$ Brix foram razoavelmente afetados pela tristeza, variando de $+3 \%$ (não significativo) a + $28 \%$ (significativo); em média, um acréscimo de $14 \%$ nos híbridos intolerantes. Quanto aos valores observados, em relação à porcentagem de acidez nos híbridos $\mathrm{C} \times \mathrm{A}$, houve um acentuado decréscimo $(-20 \%)$; nos demais, houve acréscimos entre $13 \%$ e $29 \%$, mas, em apenas um caso foi significativo. Os dados do presente trabalho não permitem maiores conjecturas a respeito de tal discrepância. Quanto à relação ${ }^{\circ}$ Brix $l \%$ acidez, verifica-se que as diferenças foram pequenas e todas não significativas, indicando que deve ter havido uma certa compensação em relação aos teores de sólidos solúveis. A tristeza, doença que afeta o sistema vascular, talvez influa no mecanismo de translocação de água e nutrientes, diminuindo, com isso o tamanho dos frutos (nesse caso, em cerca de $22 \%$ ) mas, por algum mecanismo compensatório, aumentando o teor de sólidos solúveis (aqui observado em 14\%). É conhecido o fato de que, em anos secos, plantas em cultivo não irrigado apresentam maior teor de sólidos solúveis, porém menor tamanho dos frutos.

\section{CONCLUSÕES}

1. A mortalidade no viveiro foi ao redor de $21 \%$. Dentre os sobreviventes transplantados para o campo, $13 \%$ dos indivíduos intolerantes morreram em um período de quatro anos.

2. Em quatro anos, o diâmetro dos porta-enxertos foi reduzido em $41 \%$, o do enxerto em $45 \%$, o índice de vigor vegetativo em $42 \%$.

3. A produção foi o caráter mais drasticamente afetado, reduzindo em $41 \%$ na primeira colheita, $90 \%$ na quinta colheita, com média de $85 \%$ na produção acumulada das cinco primeiras colheitas.

4. A produtividade por área da projeção da copa sofreu também acentuada redução $(46 \%)$, indicando que o decréscimo da produção foi proporcionalmente mais intenso que o do crescimento vegetativo, sendo, por esta razão, o caráter econômico mais seriamente afetado.

5. A relação diâmetro do enxerto/porta-enxerto decresceu $7 \%$. Embora pequena, mostrou que, proporcionalmente, a copa tolerante foi mais afetada que o porta-enxerto intolerante.

6. A coloração externa dos frutos, o rendimento e o ratio do suco foram pouco afetados, enquanto os valores da acidez, nos híbridos intolerantes, aumentaram em média $12 \%$ e do teor de sólidos solúveis, $14 \%$. 


\section{AGRADECIMENTOS}

Os autores agradecem aos Pesquisadores Jorgino Pompeu Junior, Gerd W. Müller e Joaquim Teófilo Sobrinho, do Centro Avançado de Pesquisa Tecnológica dos Agronegócios de Citros, pelas sugestões apresentadas durante a realização da pesquisa; a Debir N. Gomes pelo desenvolvimento do campo, a Valéria X. P. Garcia pelas análises industriais e a Silvia Luisa S. Lima, pela ajuda na digitação.

\section{REFERÊNCIAS BIBLIOGRÁFICAS}

BALLVÉ, R.M.L.; BORDIGNON, R.; MEDINA FILHO, H.P.; SIQUEIRA, W.J.; TEÓFILO SOBRINHO, J.; POMPEU JÚNIOR., J. Isoenzimas na identificação precoce de híbridos e clones nucelares no melhoramento de citros. Bragantia, Campinas, v.50, n.1, p.57-76, 1991.

BALLVÉ, R.M.L.; MEDINA FILHO, H.P.; BORDIGNON, R. Identification of reciprocal hybrids in citrus by the broadness of leaf petiole wing. Brazilian Journal of Genetics, Ribeirão Preto, v.20, n.4, p.697-702, 1997

BALLVÉ, R.M.L.; MEDINA FILHO, H.P.; BORDIGNON, R.; LIMA, M.M.A. Methodology for starch gel electrophoresis and protocols for isozyme of 32 plant genera. Brazilian Journal of Genetics, Ribeirão Preto, v.18, n.3, p.441-502, 1995.

BENNETT, C.W.; COSTA, A.S. Tristeza disease of citrus. Journal of Agricultural Research, Washington, v.78, n.8, p.207-237, 1949.

BITANCOURT, A.A. Um teste para identificação precoce da Tristeza dos Citrus. O Biológico, São Paulo, v.10, p.169-175, 1944.

BORDIGNON, R. Características agronômicas e tolerância à tristeza de híbridos entre porta-enxertos elite de citros. 2000. 164f. Dissertação (Doutorado em Genética e Biologia Molecular) - Instituto de Biologia - Universidade Estadual de Campinas.
BORDIGNON, R. Hibridações interespecíficas, intergenéricas, intergrupais, intersubtribais e intersubfamiliares de Citrus e gêneros relacionados. 1995. 104f. Dissertação (Mestrado em Genética) - Instituto de Biologia - Universidade Estadual de Campinas.

BORDIGNON, R.; MEDINA FILHO, H.P.; BALLVÉ, R.M.L. Melhoramento genético de citros no Instituto Agronômico. Laranja, Cordeirópolis, v.11, p.167-176, 1990.

FRANCO, C.M.; BACCHI, O. Investigações sobre a tristeza dos citrus. Bragantia, Campinas, v.4, n.9, p.541-551, 1944.

LEE, R.F.; BAKER, P.S.; ROCHA-PENA, M.A. The citrus tristeza virus (CTV). Ascot: International Institute of Biological Control, 1994. 195p.

MENEGHINI, M. Sobre a natureza e transmissibilidade da doença tristeza dos citrus. O Biológico, São Paulo, v.12, p.285-287, 1946.

MINITAB $^{\circledR}$ STATISTICAL SOFTWARE. Release 13.31. State College, Pennsylvania: Minitab., 2000.

MOREIRA, S. Observações sobre a tristeza dos citros ou podridão das radicelas. O Biológico. São Paulo, n.11, p.269-272, 1942.

MOREIRA, S.; COSTA, A.S.; GRANT, T.J. Conhecimentos atuais sobre a tristeza dos citrus. Revista de Agricultura, Piracicaba, v.24, n.11-12, p.335-345, 1949.

POMPEU JÚNIOR, J. Situação do uso de porta-enxertos no Brasil. In: SEMINÁRIO INTERNACIONAL DE CITROS, 1., Bebedouro. Anais... Jaboticabal: Finep, 1990. p.1-10.

ROISTACHER, C.N.; GUMPF, D.G.; DODDS, J.A.; LEE, R.F. The threat of the citrus killer. Citrograph, Fresno,v. 78, n. 10, p. 4-12, 1991.

TOXOPEUS, H. Notes on the genetics of a few leaf characters in the genus Citrus. Euphytica, Dordrecht, v.11, p.19-25, 1962. 